\title{
Two-Stage Robust Optimization Model for Fresh Cold Chain considering Carbon Emissions and Uncertainty
}

\author{
Deqiang Qu and Zhong $W u$ iD \\ Business School, University of Shanghai for Science and Technology, Shanghai 20093, China \\ Correspondence should be addressed to Zhong Wu; wuzhong_1968@163.com
}

Received 28 January 2021; Revised 14 February 2021; Accepted 23 April 2021; Published 3 May 2021

Academic Editor: Wei Zhang

Copyright (c) 2021 Deqiang Qu and Zhong Wu. This is an open access article distributed under the Creative Commons Attribution License, which permits unrestricted use, distribution, and reproduction in any medium, provided the original work is properly cited.

\begin{abstract}
Sustainable development is an everlasting theme and lasting strategy in today's era. Low-carbon economy is an inevitable approach to the implementation of sustainable development. Cold chain logistics has become one of the main sources of carbon emissions. However, in the research on location planning of cold chain logistics, the costs of carbon emissions have not been taken into consideration in previous studies. The two-stage stochastic optimization (TSSO) model was established based on the comprehensive consideration of transportation costs, time penalty costs, and carbon emission costs. In this case, it is extremely difficult to deal with uncertainty in TSSO model. Therefore, this paper constructs a two-stage robust optimization (TSRO) model using data-driven method and robust optimization theory and verifies the validity of this model through an actual case. The application of this method to a cold chain logistics enterprise showed that the service level of logistics cannot be guaranteed by stochastic optimization model. In the TSRO model, the costs increase by $2.18 \%$ at the price of robustness, whereas logistics service level shows an upward trend (from $85.83 \%$ to $92.75 \%$ ). In the TSRO model, enterprises are forced to choose a better distribution path when carbon tax increases, which not only helps enterprises save costs but also achieves low-carbon environmental benefits.
\end{abstract}

\section{Introduction}

Sustainable development is a long-standing concept of human society. The deteriorating environment is constantly challenging national sustainable development strategies. Statistics show that a significant increase in greenhouse gas emissions is the primary cause of deterioration in the ecological environment. In consequence, how to reduce carbon emissions has become an extremely urgent global issue. Governments around the world are increasingly concentrating on reducing carbon emissions in their economic activities. Under the background of advocating sustainable environmental development, it is imperative to take action on energy saving and emission reduction. Cities such as Beijing, Tokyo, and California have issued policies to promote sustainable development strategies $[1,2]$. China has discharged the largest amount of carbon dioxide since 2009 $[3,4]$. In pursuit of sustainable development, government will set caps on carbon emissions on the basis of actual capacity, while related enterprises will then make production plans. These policies and deteriorating environment make people aware of the fact that it is necessary to develop lowcarbon economy $[5,6]$.

With the rapid growth of industrial economy, the focus of decision-makers has gradually shifted from economic benefits to coordinated development of economic and environmental benefits. Previous research has focused on manufacturing, while it has been rarely concerned about transportation. In fact, the carbon emissions of transportation are enormous, especially in the cold chain logistics industry [7]. Statistics show that carbon emissions from vehicles in logistics transportation are one of the major sources of greenhouse gases worldwide. Greenhouse gases generated during logistics transport, among which large quantities of greenhouse gases come from cold chain logistics, account for $14 \%$ of those around the world $[8,9]$. Low-carbon vehicle routing problem is the research basis of traditional vehicle routing problem, which adds carbon 
emission constraints. Besides economic benefits, environmental factors should also be considered to effectively reduce carbon emissions during transportation [10].

Many literatures have studied the influence of carbon emission on logistics and transportation industry. When carbon trading mechanism exists in the market, the costs need to be considered in the logistics distribution routing problem. Hoen et al. carried out research on emission control management mechanism and suggested that policymakers should adopt carbon emission limit management mechanism [11]. The government is tightening carbon emission control to enterprises, which will inevitably result in certain economic costs. It is obviously more realistic to add carbon emission constraints when figuring out the vehicle optimal path problem. If the carbon emission in transportation can be effectively controlled, it is of great significance to promote development of low-carbon logistics. Therefore, vehicle routing optimization with carbon emission constraints is gradually becoming an important research field.

With the increase of $\mathrm{CO}_{2}$ emission and pressure of environmental pollution, many scholars pay attention to the research on carbon emission reduction of cold chain logistics enterprises. However, most of the research methods are single-stage models, and few scholars use two-stage models. Zhou et al. proposed a low carbon supply chain framework based on supply chain process criteria [12]. Others have made quantitative research on the implementation of cold chain logistics. Tang et al. proposed a benchmark model for carbon reduction [13]. Hariga et al. proposed activity-based cost minimization models and carbon footprint minimization models [14]. Elhedhli et al. proposed an optimization model for constructing food cold chain inventory and transportation network and studied the cold chain logistics transportation [15]. The carbon emission studied in this paper is an extension of traditional vehicle routing problem, and the low carbon cold chain logistics transportation planning problem in two stages is studied.

Two-stage optimization model is widely utilized in supply chain management, emergency dispatching, industrial production, energy grid, and other fields [16, 17]. In the two-stage optimization problem, previous researchers often started with deterministic model, while few scholars studied its uncertainty. Dillon et al. studied the optimization of medical supply chain network using a two-stage optimization model [18]. Weskamp et al. studied two-stage optimization of supply chain network with delayed payment strategy under uncertain demand [19]. Chen et al. studied the two-stage stochastic distribution robust linear complementarity problem [20, 21]. Lin et al. established a two-stage model considering late payment and analyzed the integrated production inventory strategy [22]. Sainathuni et al. studied the inventory-transportation problem to determine the optimal distribution plan from the supplier to the customer to minimize total costs [23]. Scenario-based stochastic optimization can work out supply chain management and system optimization problems [24, 25]. Rezaee et al. put forward the design of a green supply chain network with stochastic demand and carbon price [26]. However, the solution of scenario-based stochastic optimization model depends to a large extent on the defined scenario and its probability of occurrence, and the solution of such model will dramatically increase the amount of calculation and increase the difficulty or even no solution as the number of scenarios increases [27]. The above optimization models usually assume that the probability distribution of stochastic demand is known beforehand, which is inconsistent with the actual situation. In addition, it is difficult to deal with uncertain parameters and solve unexpected situations in production through these models.

In recent years, many scholars and experts have introduced robust optimization methods to the solution of various problems of supply chain management to improve the robustness of the model. Robust optimization model methods have been extensively studied to reduce the chance of stochastic problems. Gulpinar and Pachamanova proposed a robust optimization model for equipment location under worst-case scenarios by assuming that stochastic demand belongs to an uncertain set [28]. Zokaee et al. studied the optimization of robust supply chain networks by assuming that demand, inventory capacity, and cost parameters belong to box set [29]. This model considers that uncertain parameters belong to a set and studies the decision-making problem with minimum total costs in the worst case. In addition, robust optimization as optimization theory is widely used in many practical scenarios, such as largescale group decision-making [30], consensus decisionmaking [31], multicriteria decision-making [32], and energy forecasting [33]. The extensive application of robust optimization model in different fields makes scholars pay more attention to its expansibility. However, it is rarely found in the previous literature that robust optimization is used to study the sustainable development of cold chain. Therefore, it is more attractive to further expand the research of robust optimization.

As an effective tool for uncertain optimization, robustness optimization does not rely on the probability distribution of events but represents unknown parameters with specific sets of uncertainties. As a result, considering the uncertainty of cold chain logistics research, there are many potential benefits of extending robust optimization theory to solve the transportation problems of fresh cold chain logistics $[34,35]$. They are independent of the probability distribution of the needs of the target audience; and they maintain robustness even in the worst case. Robust optimization is introduced into cold chain logistics. However, in the research of fresh product cold chain logistics, only a few scholars use stochastic probability model, and no other scholars use two-stage robust optimization theory to study. Robust optimization can consider the risk preference and conservativeness of decision-makers to some extent, and it has important research value in the research of fresh cold chain logistics.

In conclusion, although scholars have carried out extensive research on the impact of carbon emission factors and policy factors on cold chain logistics, there are still some problems in the existing research. Firstly, the qualitative type of overview paper covers a comprehensive range of fields but 
lacks comparative analysis of data. Secondly, most of the mathematical model papers of quantitative type study lowcarbon cold chain logistics from a single angle or aspect, and the factors involved in the research are not comprehensive enough. In addition, most of the studies do not consider the impact of uncertainty parameters on logistics transportation services, which is difficult to reflect the real market operation. Few researchers use quantitative methods to study lowcarbon cold chain logistics under uncertain demand. What is more, there are few papers on the research of cold chain logistics in low-carbon economy mode using robust optimization theory in methodology. Therefore, how to apply robust optimization theory to low-carbon cold chain is particularly novel.

The contributions and innovations of this research are as follows:

(i) Carbon emission factors are introduced into the study of cold chain logistics, taking into account fixed costs, time window costs, transportation costs, and carbon emission costs. A two-stage stochastic optimization model is built according to the actual situation.

(ii) Robust optimization theory is applied to fresh cold chain logistics, and stochastic optimization model is converted into robust optimization model considering uncertainty.

(iii) Data-driven method is used to preprocess model parameters, which is more universal than stochastic optimization method and can describe the real scene more accurately.

(iv) The data from real market operation is used for simulation calculation to provide decision support for fresh cold chain transportation enterprises.

(v) It provides important theoretical support and design scheme for the green and efficient development of cold chain logistics industry distribution.

This paper studies how to construct TSRO models to discuss warehousing-transportation joint optimization under uncertain demand. The first-stage decision is node selection, and the second-stage decision is transportation route planning. First, in order to improve customer satisfaction with commodity demand, TSRO models with carbon emission constraints are considered. Unlike the classical two-stage stochastic facility location problem, the model in this chapter does not assume a preknown probability distribution of stochastic demand but obtains a feasible range by means of data-driven methods. Through such a method, the research of this paper will be more valuable and meaningful.

The rest of this paper is organized as follows. Section 2 covers description of the problem and model building. Section 3 builds TSSO model and TSRO model. Section 4 verifies the validity of the model with the aid of an example. Section 5 makes detailed analysis and comparison on the performance of the model. Section 6 summarizes the conclusions of this study and future research directions.

\section{Problem Description}

2.1. Problem Description. This paper studies the two-stage location and path planning problem of cold chain considering carbon emission (Figure 1). In this problem, fresh products are transported from the place of origin to the demand stores through the intermediate warehouses. Two types of sites are considered: candidate intermediate warehouses and demand stores. Considering cost minimization and demand responsiveness, transfer cold storage has binary functions. On the one hand, in order to meet the demand, the intermediate warehouse should consider the prestorage quantity of products; on the other hand, the goal is to minimize the total cost after meeting the demand.

In the two-stage location path planning problem, the cost types considered include the construction cost of refrigerated warehouse, vehicle operation cost, time window cost, carbon emission cost, and transportation cost. In the distribution of products, the fairness of material distribution should be ensured as far as possible, and the delay loss caused by insufficient material supply and the cost consumed in the process of storage and distribution should be minimized. Enterprises can optimize the distribution of goods from warehouse to retail store $[36,37]$. This paper merely considers the selection of warehouse and the distribution from warehouse to retail store and does not consider the upstream procurement and the sales process from retail store to customer. Under the uncertain demand environment, the first stage decision is to choose the warehouse. In the second stage, the basic inventory of the selected warehouse and the distribution proportion of goods from the warehouse to the demand site are determined. The goal of the problem is to minimize the total cost under the constraint of satisfying the demand.

2.2. Basic Assumptions. Considering the actual situation of cold chain, the following assumptions are proposed for the material scheduling problem:

(i) Path optimization problem provides distribution services from multiple distribution centers to multiple demand sites

(ii) All demand sites must obtain cold chain distribution service, and each demand site has a refrigerator car to provide delivery service

(iii) Refrigerated vehicle is the same model, with the same fuel consumption and load capacity

(iv) The geographical location and time window of the demand stores are known

(v) The vehicle runs at a constant speed, directly transports, and returns to the distribution center immediately after completing the distribution

For the convenience of introduction, the symbols of relevant parameters and decision variables are summarized as shown in Table 1. 


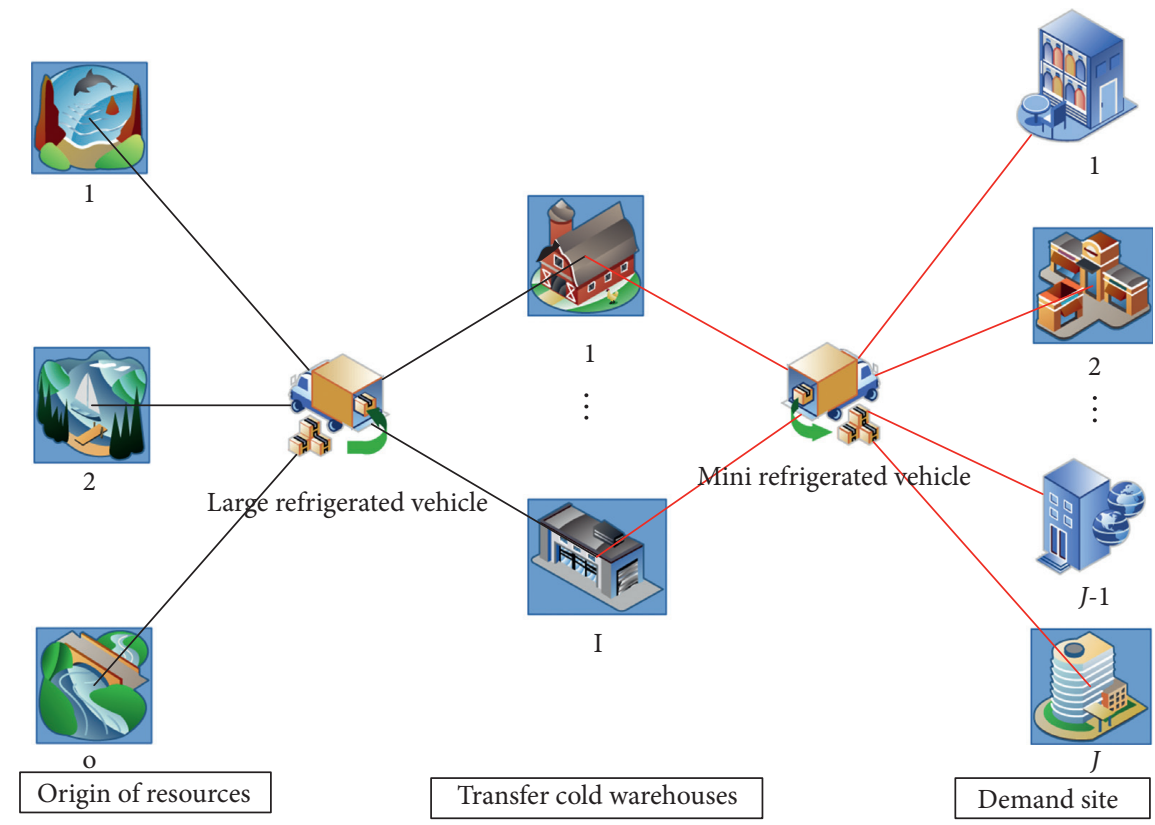

FIgURE 1: Schematic diagram of fresh cold chain path planning.

TABle 1: Description of relevant parameters and variables of the model.

\begin{tabular}{lc}
\hline Sign & Description \\
\hline$x_{i}$ & $x_{j} \in\{0,1\}, 0-1$ variable, if $x_{i} \neq 0$, select $i$ as the storage site; else, do not select; \\
$y_{i j}$ & $y_{i j} \in[0,1]$, continuous variable, if $y_{i j} \neq 0$, select the path $i j ;$ \\
$D_{j}$ & Demand \\
$c_{f}$ & Fixed cost \\
$\lambda$ & Corruption rate of fresh products \\
$H_{j}^{\mathrm{Max}}$ & Maximum inventory of transfer cold storage \\
$H_{v}$ & Maximum load capacity of large refrigerated vehicle \\
$h_{v}$ & Maximum load capacity of minirefrigerated vehicle \\
$h_{k}$ & Fuel consumption cost of unit vehicle transportation \\
$c_{v}$ & Unit consumption cost of fuel \\
$E_{c}$ & Unit fuel consumption of vehicle \\
$c_{t}$ & Unit delay penalty cost \\
$c_{e}$ & Unit carbon tax \\
$d_{o i}$ & Distance between place of origin and transfer cold storage \\
$d_{i j}$ & Distance from temporary cold storage to demand site \\
$\bar{v}_{i}$ & Average vehicle speed \\
$t_{j}$ & Base time of arrival \\
$T_{j}^{\text {Max }}$ & Maximum arrival time \\
$I$ & The set of transfer cold storages consists of $i$ \\
$J$ & The set of demand sites consists of $j$
\end{tabular}

2.3. Cost Analysis. The objective of this study is to minimize the comprehensive cost of cold chain to reflect the actual situation of cold chain transportation process. It not only considers the minimum carbon emissions but also weighs the cost of distribution under the condition of low-carbon economy. Comprehensive cost includes fixed cost, transportation cost, time cost, and carbon emission cost. The cost is explained in detail as follows.

2.3.1. Fixed Cost. Fixed costs are investment costs for infrastructure, including operating costs for cold storages, vehicle maintenance costs, and driver wages. Fixed costs are independent of inventory management and total mileage of the vehicle. The fixed costs of cold chain are calculated as follows:

$$
C_{f}=\sum_{i} f_{i}\left\lceil x_{i}\right\rceil, \quad \forall i \in \mathscr{I} .
$$

2.3.2. First-Stage Transportation Cost. The first stage is when the product is transported from its origin to a cold storage warehouse with a large capacity and a single fixed vehicle type. Therefore, the transportation costs of fresh products during this stage are as follows: 


$$
C_{t 1}=\frac{c_{t 1}}{(1-\lambda) H_{v}} \sum_{i} \sum_{j} D_{j} d_{o i}, \quad \forall i \in \mathscr{I}, \forall j \in \mathscr{F},
$$

where $c_{t 1}$ represents the unit fuel consumption cost. $H_{v}$ represents the carrying capacity of a large transport vehicle. $\lambda$ represents the corruption rate of fresh products and $1-\lambda$ represents the product survival rate $[38,39]$.

2.3.3. First-Stage Carbon Emission Cost. The first phase is when products are shipped from their origin to cold storage warehouse, where the carbon cost of cold chain is as follows:

$$
C_{e 1}=\frac{c_{e 1}}{(1-\lambda) H_{v}} \sum_{i} \sum_{j} e E_{1} D_{j} d_{o i}, \quad \forall i \in \mathscr{F}, \forall j \in \mathscr{J} .
$$

In the previous equation, $c_{c e}$ is the carbon tax amount. $E_{1}$ is the unit energy consumption. $e$ is the carbon dioxide factor.

2.3.4. Second-Stage Transportation Cost. The second stage is the transportation of fresh products from transfer cold storages to demand stores. Fresh products are precisely distributed with the following transportation costs:

$$
C_{t 2}=\frac{c_{t 2}}{h_{v}} \sum_{i} \sum_{j} D_{j} y_{i j} d_{i j}, \quad \forall i \in \mathscr{I}, \forall j \in \mathscr{J} .
$$

In the previous equation, $c_{t}$ represents the unit fuel consumption cost of mini vehicles.

2.3.5. Cost of Time Window. Time costs are penalties for time delays in the following form:

$$
C_{p}=c_{p} \sum_{i} \sum_{j} x_{i}\left(\frac{d_{i j}}{\bar{v}_{i}}-t\right), \quad \forall i \in \mathscr{F}, \forall j \in \mathscr{F},
$$

where $c_{p}$ represents the time-related unit penalty cost [40].

2.3.6. Second-Stage Carbon Emission Cost. Due to the environmental requirements of the government, a certain amount of carbon tax will be levied on the vehicle at the following cost:

$$
C_{e 2}=c_{e 2} \sum_{i} \sum_{j}\left[e d_{i j} E_{21}\left(D_{j} y_{i j}\right)+e E_{22} y_{i j} D_{j} \frac{\mathrm{d}_{i j}}{\bar{v}_{j}}\right],
$$

$$
. \forall i \in \mathscr{I}, \forall j \in \mathcal{J} \text {. }
$$

In the previous equation, $c_{e}$ is the unit carbon tax amount, $E_{21}$ is the unit oil consumption, expressed as $E_{21}=D_{j} y_{i j}\left(\eta_{\max }-\eta_{0}\right) / h_{v}+\eta_{0}, \eta_{\max }$ is the full load oil consumption, $\eta_{0}$ is the no-load oil consumption, and $E_{22}$ represents the unit oil consumption of the refrigeration equipment [41].

\section{Model Establishment}

3.1. TSSO Model. In this section, we build a two-stage stochastic optimization (TSSO) model, which aims to minimize the total cost on the basis of maximizing customer demand. The specific model is as follows:

$$
\begin{aligned}
& \min \left\{C_{f}+C_{2}\left(\widetilde{D}_{j} \mid x, y\right)\right\}, \\
& \text { s.t. } x_{i} \in\{0,1\}, \quad \forall i \in \mathscr{I} .
\end{aligned}
$$

Depending on the actual scenario, the first stage of a TSSO model aims to minimize the total cost. The first item of objective function (7) is fixed cost, which includes infrastructure investment costs, including equipment loss costs and basic hydropower costs. Fixed cost is independent of vehicle routing planning. The second cost is affected by the uncertain parameters of the second stage. Constraint (8) represents 0 - 1 variable that participates in the corresponding logistics operation if and only if $x_{i}=1$. The random variable $\varepsilon$ is defined in the probability space $P, \Xi$ and assumes that the first and second moment are precisely known beforehand; that is, $E_{P}[\varepsilon]=\mu_{0}, E_{P}\left[\left(\varepsilon-\mu_{0}\right)\left(\varepsilon-\mu_{0}\right)^{T}\right]=\Sigma_{0}>0$. The second stage of the TSSO model is shown as follows:

$$
\begin{aligned}
C_{p} & +\max _{P}\left[C_{t 1}\left(\widetilde{D}_{j}\right)+C_{t 2}\left(\widetilde{D}_{j}\right)+C_{e 1}\left(\widetilde{D}_{j}\right)+C_{e 2}\left(\widetilde{D}_{j}\right)\right] \\
& \leq C_{2}\left(\widetilde{D}_{j} \mid x, y\right),
\end{aligned}
$$

$$
\begin{aligned}
& \text { s.t. } \sum_{i} \sum_{j} y_{i j} \leq 1, \quad \forall i \in \mathscr{I}, \forall j \in \mathcal{F}, \\
& y_{i j} \leq x_{j}, \quad \forall i \in \mathscr{I}, \forall j \in \mathscr{J}, \\
& \sum_{i} \sum_{j} y_{i j} \widetilde{D}_{j} \leq H_{j}^{\mathrm{Max}}, \quad \forall i \in \mathscr{F}, \forall j \in \mathscr{J}, \\
& \left\lceil y_{i j}\right\rceil\left(\frac{d_{i j}}{\bar{v}_{j}}\right) \leq T_{i j}^{\mathrm{Max}}, \quad \forall j \in \mathscr{F}, \\
& \max _{P}\left[C_{e 1}\left(\widetilde{D}_{j}\right)+C_{e 2}\left(\widetilde{D}_{j}\right)\right] \leq C_{E}^{\mathrm{Max}}, \quad \forall j \in \mathscr{J}, \\
& P\left\{\varepsilon \mid \varepsilon \notin \Xi_{j}\right\} \leq 1-\alpha_{j}, \widetilde{D}_{j}=D_{j}^{0}+\varepsilon D_{j}^{0}, \quad \forall j \in \mathscr{J}, \\
& 0 \leq y_{i j}, x_{i} \in\{0,1\}, \quad \forall i \in \mathscr{I}, \forall j \in \mathscr{J} .
\end{aligned}
$$

In the process of solving optimization problem (7)-(16), the following difficulties will be faced. On the one hand, in practical applications, the probability distribution of random parameters is unknown. Even if it is assumed to follow a known probability distribution, the calculation of the objective function of the problem is extremely difficult for continuous random variables. There is no ideal model in real life. It is often difficult to obtain the development law of key parameters, especially the probability distribution of demand parameters. On the other hand, the model contains multiple opportunity constraints because the probability distribution of random demand is unknown. Therefore, this constraint problem is nonconvex, which is also very difficult to deal with in calculation. Based on the above two 
difficulties, the concept of robust optimization is introduced, and robust model can effectively provide an effective measure of uncertainty. Robust optimization research has higher applicability and stability than others. In this section, the above deterministic TSSO model is transformed into TSRO models by applying the relevant theory of robust optimization, so that the uncertain parameters change within the uncertain set, so that the probability distribution independent of the model can also be used to study the inventory routing problem. Based on stochastic model, initial site demand is defined as stochastic demand parameter $\widetilde{D}_{j}=D_{j}^{0}+\widehat{D}_{j}, D_{j}^{0}$ is nominal demand, $\widehat{D}_{j}=\varepsilon D_{j}^{0}$ is fluctuation demand, and $\varepsilon$ is disturbance proportion. Then, the TSRO models are established, respectively [42-44].

3.2. Box Set Two-Stage Robust Optimization (BTSRO) Model. In the BTSRO model, the uncertain demand is $\widetilde{D}_{j}$. According to the robust optimization theory, the TSSO model is further transformed into a BTSRO model, and the definition domain of uncertain parameters is $\left.\cup_{B}=\left\{\varepsilon:\|\varepsilon\|_{\infty} \leq \Psi_{j}\right\} \Leftrightarrow\left|\varepsilon_{j}\right| \leq \Psi_{j}\right\}$, and $\Psi_{j}$ represents uncertain level parameters (i.e., safety parameters), indicating that at most $\Psi_{j}$ parameters deviate from nominal values [45].

Theorem 1. With the box set uncertain parameters, when the uncertain parameter is not 0 , the BTSRO model inf $x, y$ $\left\{t: \mathbb{U}_{B}(C, A, B)\left\{\sup _{1}^{T}(\varepsilon) x \leq t \mho \sup C_{2}^{T}(\varepsilon) y \leq t \mho A^{T} x \leq B\right\}\right\}$ is equivalent to them in the TSSO model $\min x, y\left\{t: P(C, A, B)\left\{C_{1}^{T} x \leq t \& C_{2}^{T} y \leq t \& A^{T} x \leq B\right\} \quad \geq 1-\right.$ $\left.\alpha_{j}\right\}$. When the uncertain parameter is 0 , the BTSRO model degenerates into a two-stage linear optimization model.

The first stage of the BTSRO model is (17)-(19), the goal of which is how to pursue the minimization of the total cost under uncertain conditions.

$$
\begin{array}{ll} 
& \inf Z_{B}, \\
\text { s.t. } & \sup _{\cup_{B}}\left(C_{f}+C_{2}\left(\widetilde{D}_{j} \mid x, y\right)\right) \leq Z_{B}, \\
& x_{i} \in\{0,1\}, \quad \forall i \in \mathscr{I} .
\end{array}
$$

The second stage of the BTSRO model is (20)-(27) with the goal of pursuing a minimized distribution cost on the basis of maximizing the met customer demand.

$$
\begin{aligned}
& \inf _{\cup_{B}} C_{2}\left(\widetilde{D}_{j} \mid x, y\right), \\
& \text { s.t. } C_{p}+\left\{C_{t 1, t 2}\left(D_{j}^{0}\right)+C_{e 1, e 2}\left(D_{j}^{0}\right)+\sup _{\cup_{B}} \Psi_{j}\right. \\
& \left.\cdot\left[C_{t 1, t 2}\left(\widehat{D}_{j}\right)+C_{e 1, e 2}\left(\widehat{D}_{j}\right)\right]\right\} \leq C_{2}, \\
& \sum_{i} \sum_{j} y_{i j} \leq 1, \quad i \in I, \forall j \in \mathscr{J},
\end{aligned}
$$

$$
\begin{aligned}
& \sum_{i} \sum_{j} y_{i j} D_{j}^{0}+\Psi_{j}^{\prime} \sum_{i} \sum_{j} y_{i j} \widehat{D}_{j} \leq H_{j}^{\mathrm{Max}}, \quad \forall i \in \mathscr{I}, j \in \mathscr{J}, \\
& \left\lceil y_{i j}\right\rceil \cdot\left(\frac{d_{i j}}{\bar{v}_{j}}\right) \leq T_{i j}^{\mathrm{Max}}, \quad \forall j \in \mathscr{J}, \\
& \sup _{\cup_{B}}\left[C_{e 1}\left(\widetilde{D}_{j}\right)+C_{e 2}\left(\widetilde{D}_{j}\right)\right] \leq C_{E}^{\mathrm{Max}}, \quad \forall j \in \mathscr{J}, \\
& \mathscr{P}\left\{\varepsilon \mid \varepsilon \notin \cup_{B}\right\} \leq 1-\alpha_{j}, \quad \forall j \in \mathscr{J}, \\
& 0 \leq y_{i j} \leq x_{i}, x_{i} \in\{0,1\}, \quad \forall i \in \mathscr{I}, \forall j \in \mathscr{J} .
\end{aligned}
$$

Proof. In stochastic optimization (SO), the uncertain numerical data are assumed to be random. In the simplest case, these random data obey the probability distribution that is known in advance, while, in more advanced settings, this distribution is only partially known. Here again an uncertain problem is associated with a deterministic counterpart, most notably with the chance constrained problem $\min x, y\left\{t: P(C, A, B)\left\{C_{1}^{T} x \leq t \& C_{2}^{T} y \leq t \& A^{T} x \leq B\right\} \geq\right.$ $\left.1-\alpha_{j}\right\}$, where $\alpha_{j} \ll 1$ is a given tolerance and $P$ is the distribution of the data $(C, A, B)$. When this distribution is only partially known, all we know is that $P$ belongs to a given family $\mathbb{P}$ of probability distributions on the space of the data. The above setting is replaced with the constrained setting. The stochastic optimization approach seems to be more conservative than the worst-case-oriented robust optimization approach. In the stochastic optimization model, the probability distribution of parameters in the model is required to be high, and a large amount of historical data is frequently needed for reasoning and analysis. Therefore, the feasibility of stochastic optimization is not high. We transform it into a robust optimization model. Set $\mathbb{P}_{\infty}=$ $\left[\mathscr{J}_{L \times L} ; \mathbb{O}_{1 \times L}\right], \mathscr{P}_{\infty}=\left[\mathscr{O}_{L \times 1} ; \Psi\right] \ldots \infty=\left\{\left[\theta_{L \times 1} ; t\right]:\|\theta\|_{\infty}=t\right\}$, where $L$ is the number of uncertain parameters. The parameters of the model change from uncertain distribution probability $\mathbb{P}$ to uncertain set $\mathbb{U}_{B}$. The original probability distribution constraint form, $P(C, A, B)\left\{C_{1}^{T} x \leq\right.$ $\left.t \& C_{2}^{T} y \leq t \& A^{T} x \leq B\right\} \geq 1-\alpha_{j}$ (i.e., $\mathbb{P}(.) \geq 1-\varepsilon$ ) for all $P \in \mathbb{P})$, is transformed into robust optimization form $\mathbb{U}_{B}(C, A, B)\left\{\sup _{1}^{T}(\varepsilon) x \leq t \& \sup C_{2}^{T}(\varepsilon) y \leq t \& A^{T} x \leq B\right\} \quad$ (i.e., $\left.\sup _{n}^{T}(\varepsilon) x \leq t\right)$ for all $\left.n \in\{1,2, \ldots, n-1, n\}\right)$, where $t$ is the corresponding right-hand constraint. So, Theorem 1 is proved.

\subsection{Ellipsoid Set Two-Stage Robust Optimization (ETSRO)} Model. In the ETSRO model, the uncertain demand is $\widetilde{D}_{j}$ and the uncertain parameters belong to the set of ellipsoids [46]. $\left\{\left\{\cup_{E}\right\} \mid\|\varepsilon\|_{2} \leq \Omega_{j} \Leftrightarrow \varepsilon \sqrt{\sum_{J} \varepsilon_{j}^{2}} \leq \Omega_{j}\right\} \Rightarrow\left\{\widetilde{D}_{j} \in \mathbb{R}, \sum_{J}\left[\left(\widetilde{D}_{j}-\right.\right.\right.$ $\left.\left.\left.\left.D_{j}^{0}\right) / \widehat{D}_{j}\right]^{2} \leq \Omega_{j}^{2}\right\}\right\}$ is defined according to $l_{2}$ norm, of which $\Omega_{j}$ is an adjustable security parameter. This is a nonlinear constraint $\quad$ problem, $\quad\left\{\cup_{E}\right\} \Leftrightarrow\left\{\widetilde{D} \in \mathbb{R},\left(\widetilde{D}_{j}-D_{j}\right)^{T}\right.$ 
$\left.C^{-1}\left(\widetilde{D}_{j}-D_{j}\right) \leq \Omega_{j}^{2}\right\}$, where $C$ is an $n$-order diagonal matrix with elements; then $C\left(D_{j}^{0}\right)+\Omega_{j} \sqrt{\sum_{J}\left(\widehat{D}_{j}^{2}\right)\left[\sum_{I, J}\left(y_{i j}\right) c_{t}\right]^{2}} \leq$ $Z_{E}$.

Theorem 2. With the ellipsoid set uncertain parameters, when the uncertain parameter is not 0, the ETSRO model $\inf x, y\left\{t: \mathbb{U}_{E}(C, A, B)\left\{\sup C_{1}^{T}(\varepsilon) x \leq t \mho \sup C_{2}^{T}\right.\right.$

(e) $\left.y \leq t \& A^{T} x \leq B\right\}$ is equivalent to them in the TSSO model $\min x, y\left\{t: P(C, A, B)\left\{C_{1}^{T} x \leq t \prec C_{2}^{T} y \leq t \diamond A^{T} x \leq B\right\} \geq\right.$ $\left.1-\alpha_{j}\right\}$. When the uncertain parameter is 0 , the ETSRO model degenerates into a two-stage linear optimization model.

The first stage of ETSRO model is (28)-(30), and the goal is how to pursue the minimization of the total cost under the condition that the uncertain parameters obey the ellipsoid set.

$$
\begin{aligned}
& \inf _{\cup_{E}} Z_{E}, \\
& \text { s.t. } C_{f}+\sup _{\cup_{E}}\left[C_{2}\left(\widetilde{D}_{j} \mid x, y\right) \leq Z_{E},\right. \\
& x_{i} \in\{0,1\}, \quad \forall i \in \mathscr{I} .
\end{aligned}
$$

The second stage of the ETSRO model is (31)-(41), which aims to pursue a minimized path transportation cost on the basis of maximizing the met demand.

$$
\begin{aligned}
& \inf _{\cup_{E}} Z_{E} C_{2}\left(\widetilde{D}_{j} \mid x, y\right) \text {, } \\
& \text { s.t. } C_{2}\left(D_{j}^{0}\right)+\Omega_{j} \Upsilon_{j}+\sup _{\cup_{E}}\left[C_{3}\left(\widetilde{D}_{i}\right)\right] \leq C_{2} \text {, } \\
& C_{p}+C_{t 1, t 2}\left(D_{j}^{0}\right)+C_{e 1, e 2}\left(D_{j}^{0}\right) \leq C_{2}\left(D_{j}^{0}\right), \\
& \Upsilon_{j} \geq \sqrt{\sum_{j \in J} \widehat{D}_{j}^{2} r_{i}^{\prime 2}}, \quad \forall i \in \mathscr{I}, \forall j \in \mathcal{F}, \\
& r_{j}^{\prime} \geq \sum_{i} \sum_{j}\left(x_{j} c_{h}^{2} y_{i j}+\frac{c_{v}^{2} y_{i j} d_{i j}}{h_{j}}\right), \quad \forall i \in \mathscr{F}, \forall j \in \mathscr{F}, \\
& \sum_{i} \sum_{j} y_{i j} D_{j}^{0}+\Omega_{j} \Upsilon_{j} \leq H_{j}^{\mathrm{Max}}, \quad \forall i \in I, \\
& \sum_{i} \sum_{j} y_{i j} \leq 1, \quad \forall j \in \mathcal{F}, \\
& \left\lceil y_{i j}\right\rceil \cdot\left(\frac{d_{i j}}{\bar{v}_{j}}\right) \leq T_{i j}^{\mathrm{Max}}, \quad \forall j \in \mathcal{F}, \\
& \sup _{\cup_{E}}\left[C_{e 1}\left(\widetilde{D}_{j}\right)+C_{e 2}\left(\widetilde{D}_{j}\right)\right] \leq C_{E}^{\mathrm{Max}}, \quad \forall j \in \mathcal{F}, \\
& \mathscr{P}\left\{\varepsilon \mid \varepsilon \notin \cup_{E}\right\} \leq \alpha_{j}, \quad \forall j \in \mathscr{J},
\end{aligned}
$$

$$
0 \leq y_{i j} \leq x_{i}, x_{i} \in\{0,1\}, \quad \forall i \in \mathscr{I}, \forall j \in \mathscr{J} .
$$

Proof. It is similar to the BTSRO model proof method. In the ETSRO model, the uncertain set is transformed from probability distribution constraint $\mathbb{P}(.) \geq 1-\varepsilon$ to uncertain robust constraint $\sup _{n}^{T}(\varepsilon) x \leq t$. In addition, the constraints of the model are scaled down appropriately, $\Upsilon_{j} \geq \sqrt{\sum_{j \in J} \widehat{D}_{j}^{2} r_{i}^{\prime 2}}, \quad$ and $\quad r_{j}^{\prime} \geq \sum_{i, j}\left(C_{n}^{T} x \leq B\right), A^{T} x \leq B, C, A$, $B \in \mathbb{U}_{E}$. For general constraints of the model, define $\cup_{E}=\left\{a_{i} \in R^{n}: a_{i}=\bar{a}_{i}+\Delta \xi, \xi \leq \Omega\right\}$, where $\Delta=\sum^{1 / 2}$, and the constraints $\max a_{i}^{T} X \leq B$ of it can be translated as $\max \left\{a_{i}^{T} X:\left(a_{i}-\bar{a}_{i}\right)^{T} \Sigma^{-1}\left(a_{i}-\bar{a}_{i}\right) \in \Omega^{2}\right\}$. As for $\Sigma$ is positive, so it is a convex problem. Set $\mathbb{P}_{2}=\left[\mathscr{F}_{L \times L}\right.$; $\left.\mathbb{O}_{1 \times L}\right], \mathscr{P}_{2}=\left[\mathcal{O}_{L \times 1} ; \Omega_{j}\right], \ldots 2=\left\{\left[\theta_{L \times 1} ; t\right]:\|\theta\|_{2}=t\right\}$, where $L$ is the number of uncertain parameters. The parameters of the model change from uncertain distribution probability $\mathbb{P}$ to uncertain set $\mathbb{U}_{E}$. The original probability distribution constraint form, $P(C, A, B)\left\{C_{1}^{T} x \leq t \& C_{2}^{T} y \leq t \& A^{T} x \leq B\right\} \geq$ $1-\alpha_{j}$, is transformed into robust counterpart form $\mathbb{U}_{E}(C, A, B)\left\{\sup C_{1}^{T}(\varepsilon) x \leq t \&, \ldots, \sup _{n}^{T}(\varepsilon) y \leq t \& A^{T} x \leq B\right\}$, where $t$ is the corresponding right-hand constraint. The latter is called the robust counterpart of the original uncertain problem.

So, Theorem 2 is proved.

\section{Simulation Experiment}

This section verifies the effectiveness of the proposed model in solving cold chain management problems through simulation. This paper selects a cold chain company in Zhejiang Province (coastal eastern China). The company is engaged in cold chain transportation and distribution services. Products are transported from Zhoushan aquatic products trading center to inland demand sites through transit warehouse, as shown in Figure 2. In the process of production and operation, the transportation department is faced with vehicle location and path planning problem. Due to the perishability of products, strict cold chain technology must be adopted for storage and transportation. On the basis of comprehensive consideration of related costs, the following numerical case simulation is carried out.

The first stage is the location problem of transfer of cold storage sites. Due to the perishability of fresh products, it strongly depends on cold fresh technology for storage and transportation. In the process of transportation, fresh products require the whole cold chain, once exposed to normal-temperature or high-temperature environment, it is easy to rot. In site selection, the feasibility of transportation cost and the convenience of transportation distance should be considered. Therefore, the location problem is very important. In this section, through screening, we selected Jifeng cold storage, Michaelis cold storage, Liheng cold storage, Fenghua Xiwu cold storage, and friendship cold storage factory as alternative sites. They are represented by 


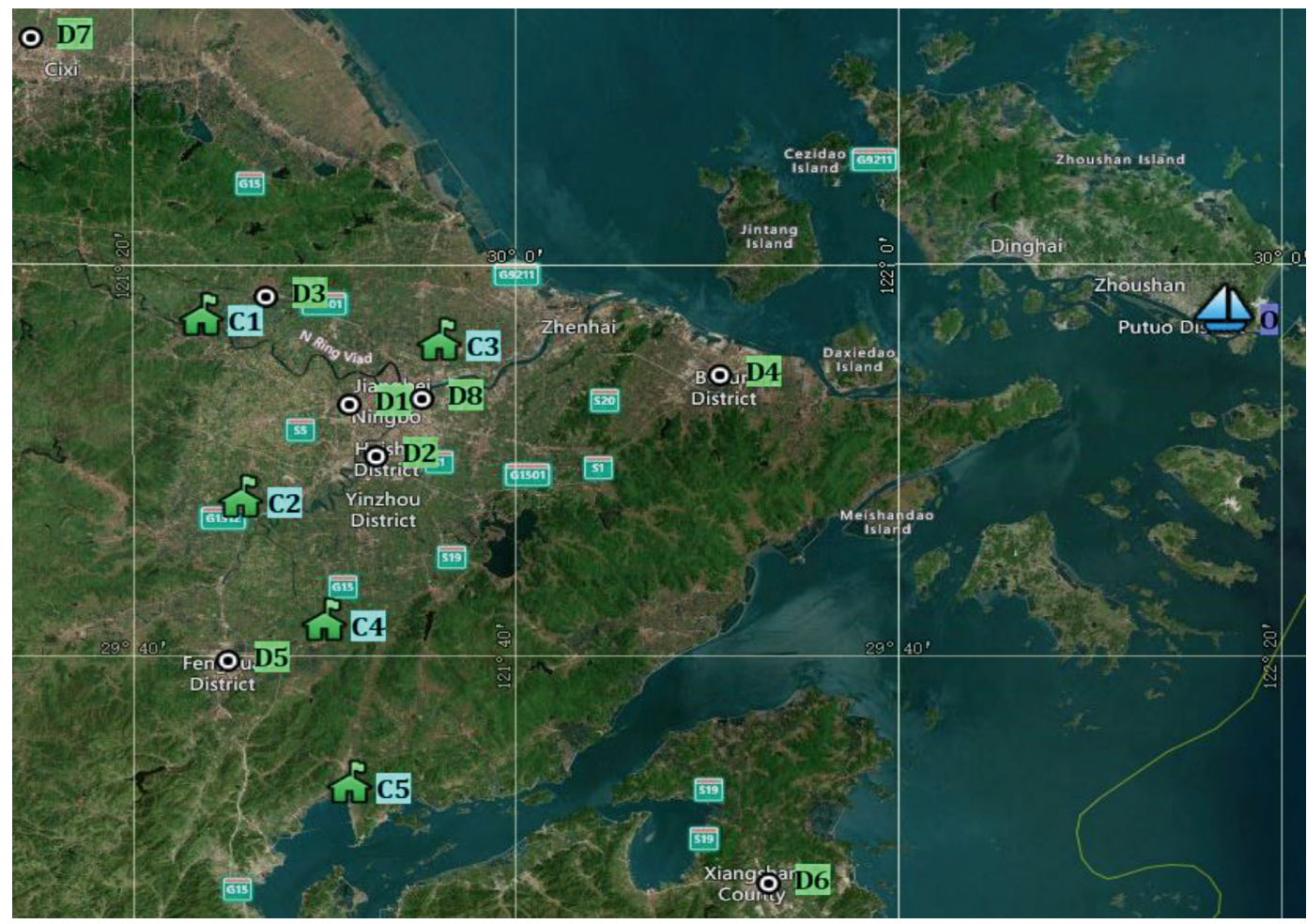

FIgURE 2: Logistics transportation scenario.

$C 1, C 2, C 3, C 4$, and C5. The goal of the first stage is to determine the location site and calculate the total cost.

The second stage is path planning. There are 5 alternative transfer cold storages and 8 demand sites. The demand sites are Walmart (plant doctor store), Walmart Shopping Plaza (Ningbo Siming Middle Road store), Metro RT Mart, Carrefour (Beilun store), RT Mart (Nanshan Road store), RT Mart (Xiangshan store), RT Mart (Cixi store), and Carrefour (Jiangdong store), which are expressed by $D 1, D 2, D 3, D 4, D 5, D 6, D 7$, and $D 8$. The goal of the second stage is to minimize the initial distribution cost, including material handling cost, transportation cost, and time cost. In the process of calculation, the setting of transportation cost is based on the comprehensive calculation of real-time oil price and actual distance and even involves factors such as traffic congestion and time limit. On the basis of comprehensive consideration of related costs, the following numerical case simulation is carried out in this section.

4.1. Relevant Data Acquisition. The basic data information includes the fixed operating cost, demand, average vehicle speed of shelter hospital, demand of designated hospital, and vehicle speed (Table 2).

This section directly obtains the actual distance between sites through Google Maps, as shown in Table 3. The vehiclerelated parameters are listed (Table 4 ).

Other parameters of the model are as follows. In addition, the energy consumption of refrigeration equipment is $0.25 \mathrm{~L} / \mathrm{h} * \mathrm{t}$, and the emission coefficient of $\mathrm{CO}_{2}$ is $2.61 \mathrm{~kg} /$ L $[41,47,48]$.
TABLE 2: Basic parameters.

\begin{tabular}{lccccc}
\hline Transfer cold storages & $C_{1}$ & $C_{2}$ & $C_{3}$ & $C_{4}$ & $C_{5}$ \\
\hline Distance & 110.6 & 127.8 & 88.5 & 134.1 & 153.9 \\
Maximum inventory & 160 & 170 & 140 & 135 & 140 \\
Average speed & 56 & 47 & 48 & 62 & 50 \\
Fixed cost & 17,500 & 16,500 & 15,500 & 14,500 & 13,200 \\
Demand site & $D_{1}$ & $D_{2}$ & $D_{3}$ & $D_{4}$ & $D_{5}$ \\
Nominal demand & 55 & 45 & 40 & 35 & 60 \\
Demand site & $D_{6}$ & $D_{7}$ & $D_{8}$ & - & - \\
Nominal demand & 50 & 75 & 68 & - & - \\
\hline
\end{tabular}

TABle 3: Distance between sites.

\begin{tabular}{lcccccccc}
\hline Distance & $D_{1}$ & $D_{2}$ & $D_{3}$ & $D_{4}$ & $D_{5}$ & $D_{6}$ & $D_{7}$ & $D_{8}$ \\
\hline$C_{1}$ & 24.6 & 26.3 & 26.4 & 53.2 & 41.3 & 92.8 & 48.7 & 32.9 \\
$C_{2}$ & 26.9 & 19.2 & 30.4 & 54.2 & 20.9 & 80.9 & 77.2 & 34.9 \\
$C_{3}$ & 15.3 & 16.4 & 22.4 & 30.2 & 39.8 & 76.5 & 63.6 & 8.7 \\
$C_{4}$ & 27.3 & 21.4 & 44.3 & 53.1 & 11.1 & 67.5 & 89.4 & 28.9 \\
$C_{5}$ & 45.3 & 37.8 & 58.7 & 67.5 & 25.4 & 64.3 & 107.5 & 45.7 \\
\hline
\end{tabular}

4.2. Results of Two-Stage Stochastic Optimization Model. In this section, we use MATLAB as the programming platform and use the solvers Gurobi $(G)$ and CPLEX (C), respectively, to solve the above models. The results of the two-stage stochastic optimization model are shown in Table 5.

In the TSSO model, the operation results of the model are affected by the probability distribution of random parameters. In this section, the common probability distribution is selected for simulation experiment. With the increase of the mean value of random parameters 
TABLE 4: Vehicle related parameters.

\begin{tabular}{lccccc}
\hline Types & Length & Max-loading & Transportation cost & Fuel & Corruption rate \\
\hline Large & $5.6 \mathrm{~m}$ & $5-8 \mathrm{t}$ & $20 \mathrm{CNY} / \mathrm{km}$ & $25.5 \mathrm{~L}$ & 0.03 \\
Small & $3.6 \mathrm{~m}$ & $3-5 \mathrm{t}$ & $12 \mathrm{CNY} / \mathrm{km}$ & $14.4 \mathrm{~L}$ & 0.04 \\
\hline
\end{tabular}

TABLE 5: Calculation results of TSSO model.

\begin{tabular}{|c|c|c|c|c|c|c|c|}
\hline Type & Mean & Cost (G) & Cost $(\mathrm{C})$ & Sites & Time $(\mathrm{G})$ & Time (C) & Gap \% \\
\hline Uniform & 0.10 & $9.13 E+04$ & $9.13 E+04$ & $1,2,3,4,5$ & $366.9 \mathrm{~ms}$ & $642.1 \mathrm{~ms}$ & $<0.01$ \\
\hline Weibull & 0.10 & $9.11 E+04$ & $9.12 E+04$ & $1,2,3,4,5$ & $396.8 \mathrm{~ms}$ & $635.3 \mathrm{~ms}$ & $<0.01$ \\
\hline Normal & 0.10 & $9.17 E+04$ & $9.17 E+04$ & $1,2,3,4,5$ & $320.5 \mathrm{~ms}$ & $631.3 \mathrm{~ms}$ & $<0.01$ \\
\hline Bernoulli & 0.10 & $9.15 E+04$ & $9.14 E+04$ & $1,2,3,4,5$ & $366.8 \mathrm{~ms}$ & $639.6 \mathrm{~ms}$ & $<0.01$ \\
\hline Exponential & 0.10 & $9.58 E+04$ & $9.58 E+04$ & $1,2,3,4,5$ & $370.0 \mathrm{~ms}$ & $633.2 \mathrm{~ms}$ & $<0.01$ \\
\hline Gamma & 0.10 & $9.16 E+04$ & $9.17 E+04$ & $1,2,3,4,5$ & $381.5 \mathrm{~ms}$ & $636.1 \mathrm{~ms}$ & $<0.01$ \\
\hline Poisson & 0.10 & $9.17 E+04$ & $9.17 E+04$ & $1,2,3,4,5$ & $336.3 \mathrm{~ms}$ & $646.9 \mathrm{~ms}$ & $<0.01$ \\
\hline
\end{tabular}

$(0.02 \longrightarrow 0.20)$, the total cost shows an upward trend $(9.13 E+04 \longrightarrow 9.58 E+04)$. There are five level-1 rescue sites opened. Acting on the different distribution, the total cost of emergency management is also quite different. This implies that, in the stochastic model, the change of parameters directly affects the total cost. However, under the circumstances of actual emergency, the development of the situation has great uncertainty frequently. It is difficult to obtain sufficient historical data to calculate the specific distribution function of parameters or even to accurately estimate the mean and variance of parameters, so the feasibility of stochastic optimization model in emergency management is low. It can be seen from the comparison of computational efficiency and performance of the model that two kinds of solvers are used to solve the model. The speed of Gurobi is at least 1.5 times faster than that of CPLEX. Obviously, Gurobi is better than CPLEX. It is found that there is a relationship Gap $<0.01$ in the error comparison, which shows that the two algorithms are effective.

\subsection{Results of Data-Driven Two-Stage Robust Optimization} Model. The existence of big data service platform provides a strong guarantee for the specific demand value of samples collected before the route planning, so that the two-stage stochastic programming problem in this paper can be transformed into a more practical decision-making problem.

As shown in Figure 3, with the big data service platform as the core, a complete process from data input, data collection to data analysis, and processing is constructed. Among them, the data processing end plays a dual role in the collection of demand data: on the one hand, the data processing end connects with the big data service platform, within the feasible authority, directly obtains the user's personal data from the platform, plays the role of text mining, and obtains the original data. On the other hand, the collected data are cleaned to obtain the key parameters.

The specific data processing steps are shown in Table 6.

Through the above steps, this paper obtains the basic sample data set of the region. The fitting interval shown in Table 7 can be obtained by normalizing the sample data. The validity of the interval is represented by the coverage of sample requirements. The range of fluctuation parameters of the sampled data is used as the classification basis, and the coverage rate is used to measure the advantages and disadvantages. Through MATLAB programming, the following results are obtained.

It can be seen that, with the increase of safety parameters, the two total costs show a gradual upward trend. When the safety parameter is 0 , the two-stage robust optimization model is equivalent to the two-stage stochastic chance constrained model. In the two-stage box set robust optimization model, when the safety parameter increases from 1 to 8 , the total cost increases from $9.23 E+04$ to $9.48 E+04 \mathrm{CNY}$, with an increase of $2.71 \%$. In the ellipsoid set two-stage robust optimization model, when the safety parameter increases from 1 to 8 , the total cost increases from $9.23 E+04$ to $9.47 E+04 \mathrm{CNY}$, with an increase of $2.54 \%$. These rising costs are the cost of robustness. It is found that the ETSRO model is more robust. In terms of demand coverage, the larger the upper and lower bounds of demand fluctuation are, the wider the coverage is. When the upper and lower bounds of demand fluctuation change from \pm 0.05 to \pm 0.10 , the coverage increases from $95.90 \%$ to $99.00 \%$.

4.4. Path Planning Scheme Based on Model. From Table 8, it can be seen that, under the TSSO model, the first stage is about the location of the cold storages, and $C 1, C 2, C 4, C 5$ are chosen. The second stage is the path planning. The proportion of transportation is mainly $C 1, C 2,37.34 \%$ and $26.07 \%$ of total demand, respectively. It is responsible for the supply of main materials to meet the needs of demand site.

From Table 9, it can be seen that, under the BTSRO model, the first stage is to choose the location of the cold storage, and $C 1, C 2, C 3, C 4, C 5$ are chosen. Compared with the TSSO model, the number of the sites increases by $C 3$. The second stage is path planning, with $C 1, C 5$ as the main transshipment proportion, accounting for $36.31 \%$ and $23.30 \%$ of the total demand, respectively, to meet the needs of all required sites.

From Table 10, it can be seen that, under the TSRO model of the oval collection, the first stage is about the location of the cold storage, and $C 1, C 2, C 3, C 4, C 5$ are chosen. Compared with the TSSO model, the new station $C 3$ 


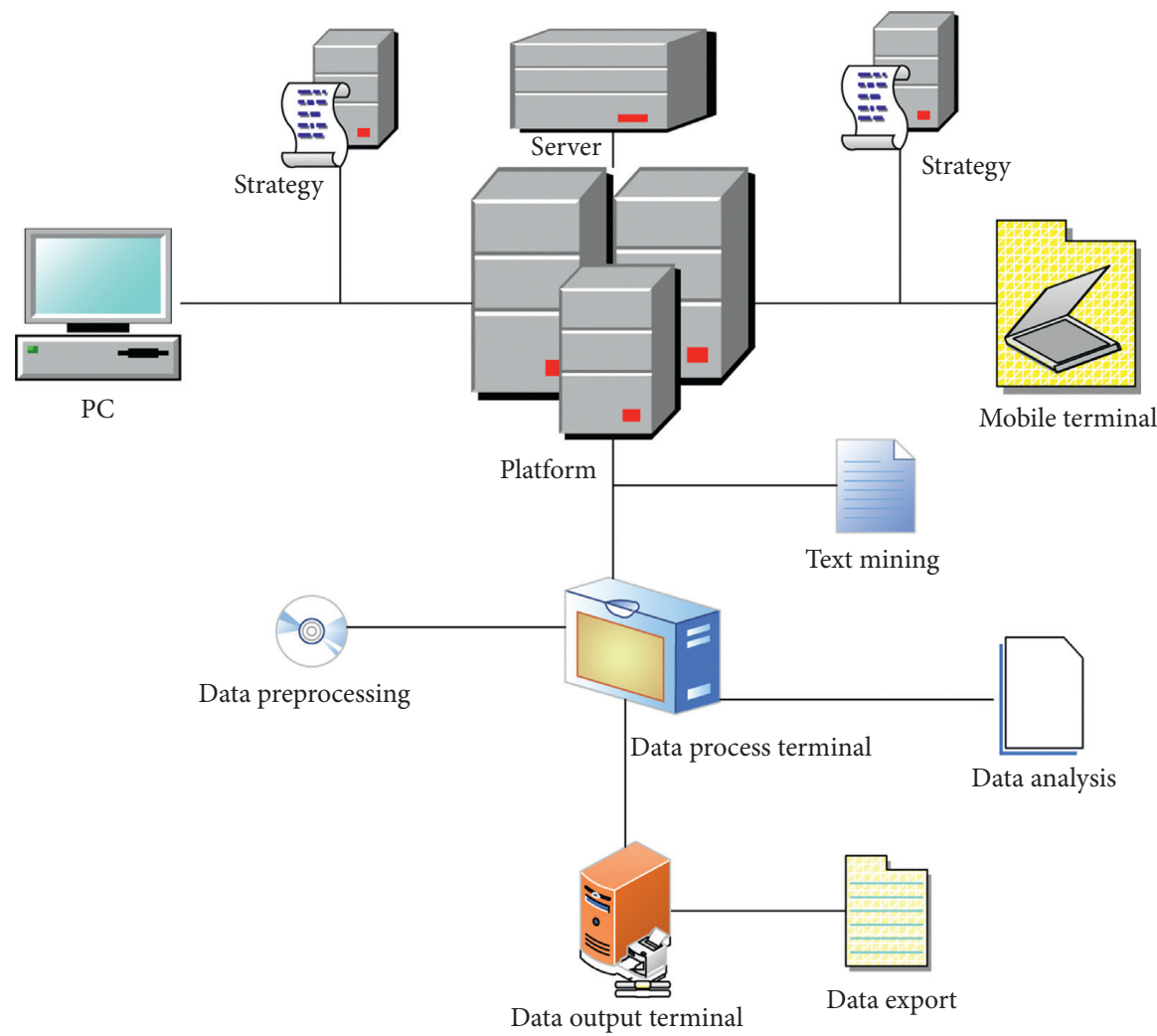

FIgURE 3: Data acquisition and processing based on platform.

TABLE 6: Detailed explanation of data processing steps.

Step Specific description

Step $1 \quad$ Original data collection: with the help of big data service platform, mining the sample set of demand through text; Step 2 Data cleaning: eliminate incomplete data; set filtering range to eliminate data group with abnormal value;

Step $3 \quad$ Data processing: fitting regression analysis of sample set data;

Step 4 Demand estimation: with the help of the parameter index of the sample data set, the overall demand parameters are estimated; Step 5 Input the initial value, input the constraint variables, and set the parameters to obey the probability distribution;

Step $6 \quad$ Input parameter variable constraints, storage capacity constraints and time window constraints, etc.;

Step 7 The solution environment is set and solved by the solver |Gurobi;

Step $8 \quad$ If step 2 is satisfied, terminate; if not, reexecute step 1;

Step 9 If the model converges or iterates to a certain number of times, the optimal solution is output.

TABLE 7: Results of a two-stage robust optimization model.

\begin{tabular}{|c|c|c|c|c|c|c|c|}
\hline \multirow[b]{2}{*}{ SP } & \multirow[b]{2}{*}{$\varepsilon$} & \multicolumn{3}{|c|}{ BTSRO model } & \multicolumn{3}{|c|}{ ETSRO model } \\
\hline & & Cost & Time & Coverage (\%) & Cost & Time & Coverage $(\%)$ \\
\hline 1 & \pm 0.05 & $9.23 E+04$ & $411.60 \mathrm{~ms}$ & 95.50 & $9.23 E+04$ & $399.25 \mathrm{~ms}$ & 95.90 \\
\hline 2 & \pm 0.05 & $9.25 E+04$ & $405.52 \mathrm{~ms}$ & 95.50 & $9.23 E+04$ & $393.36 \mathrm{~ms}$ & 95.90 \\
\hline 3 & \pm 0.05 & $9.27 E+04$ & $401.02 \mathrm{~ms}$ & 95.50 & $9.25 E+04$ & $388.99 \mathrm{~ms}$ & 95.90 \\
\hline 4 & \pm 0.05 & $9.30 E+04$ & $409.74 \mathrm{~ms}$ & 95.50 & $9.28 E+04$ & $397.45 \mathrm{~ms}$ & 95.90 \\
\hline 5 & \pm 0.05 & $9.31 E+04$ & $411.21 \mathrm{~ms}$ & 95.50 & $9.29 E+04$ & $398.87 \mathrm{~ms}$ & 95.90 \\
\hline 6 & \pm 0.05 & $9.33 E+04$ & $416.11 \mathrm{~ms}$ & 95.50 & $9.32 E+04$ & $403.62 \mathrm{~ms}$ & 95.90 \\
\hline 7 & \pm 0.05 & $9.35 E+05$ & $417.68 \mathrm{~ms}$ & 95.50 & $9.35 E+05$ & $405.15 \mathrm{~ms}$ & 95.90 \\
\hline 8 & \pm 0.05 & $9.39 E+04$ & $408.27 \mathrm{~ms}$ & 95.50 & $9.38 E+04$ & $396.02 \mathrm{~ms}$ & 95.90 \\
\hline 1 & \pm 0.10 & $9.24 E+04$ & $423.85 \mathrm{~ms}$ & 98.50 & $9.23 E+04$ & $411.13 \mathrm{~ms}$ & 99.00 \\
\hline 2 & \pm 0.10 & $9.27 E+04$ & $412.09 \mathrm{~ms}$ & 98.50 & $9.26 E+04$ & $399.73 \mathrm{~ms}$ & 99.00 \\
\hline 3 & \pm 0.10 & $9.31 E+05$ & $415.13 \mathrm{~ms}$ & 98.50 & $9.31 E+05$ & $402.67 \mathrm{~ms}$ & 99.00 \\
\hline 4 & \pm 0.10 & $9.35 E+04$ & $413.66 \mathrm{~ms}$ & 98.50 & $9.34 E+04$ & $401.25 \mathrm{~ms}$ & 99.00 \\
\hline 5 & \pm 0.10 & $9.39 E+04$ & $414.93 \mathrm{~ms}$ & 98.50 & $9.38 E+04$ & $402.48 \mathrm{~ms}$ & 99.00 \\
\hline 6 & \pm 0.10 & $9.41 E+04$ & $418.07 \mathrm{~ms}$ & 98.50 & $9.40 E+04$ & $405.53 \mathrm{~ms}$ & 99.00 \\
\hline 7 & \pm 0.10 & $9.45 E+05$ & $420.32 \mathrm{~ms}$ & 98.50 & $9.45 E+05$ & $407.71 \mathrm{~ms}$ & 99.00 \\
\hline 8 & \pm 0.10 & $9.48 E+04$ & $421.40 \mathrm{~ms}$ & 98.50 & $9.47 E+04$ & $408.76 \mathrm{~ms}$ & 99.00 \\
\hline
\end{tabular}


TABLE 8: Path planning of TSSO model.

\begin{tabular}{ccccccccc}
\hline & $D_{1}$ & $D_{2}$ & $D_{3}$ & $D_{4}$ & $D_{5}$ & $D_{6}$ & $D_{7}$ & $D_{8}$ \\
\hline$C_{1}$ & & 1 & & & 0.987 & 1 & & \\
$C_{2}$ & 0.085 & & & 1 & & & & 1 \\
$C_{3}$ & & & & & & & & \\
$C_{4}$ & & & 1 & & 0.013 & & 1 & \\
$C_{5}$ & 0.915 & & & & & & & \\
\hline
\end{tabular}

TABLE 9: Path planning of BTSRO model.

\begin{tabular}{ccccccccc}
\hline & $D_{1}$ & $D_{2}$ & $D_{3}$ & $D_{4}$ & $D_{5}$ & $D_{6}$ & $D_{7}$ & $D_{8}$ \\
\hline$C_{1}$ & 0.905 & & 1 & & & & 1 & \\
$C_{2}$ & & 0.753 & & 0.549 & 0.213 & & & \\
$C_{3}$ & 0.095 & & & 0.451 & & & & 0.136 \\
$C_{4}$ & & 0.247 & & & 0.787 & & & \\
$C_{5}$ & & & & & & 1 & & 0.864 \\
\hline
\end{tabular}

TABle 10: Path planning of ETSRO model.

\begin{tabular}{ccccccccc}
\hline & $D_{1}$ & $D_{2}$ & $D_{3}$ & $D_{4}$ & $D_{5}$ & $D_{6}$ & $D_{7}$ & $D_{8}$ \\
\hline$C_{1}$ & 0.925 & & 1 & & & & 1 & \\
$C_{2}$ & & 0.453 & & & 0.713 & & & \\
$C_{3}$ & 0.075 & & & 1 & & & & 1 \\
$C_{4}$ & & 0.547 & & & 0.287 & & & \\
$C_{5}$ & & & & & & 1 & & \\
\hline
\end{tabular}

is chosen. The second stage is the path planning problem. The center of gravity of transportation is different from the two stages of the oval collection. The TSRO model consisted of $C 1, C 3,36.56 \%$ and $25.94 \%$, respectively. Compared with the first two models, the load on some of the sites of the TSSO model is too heavy. The luck proportion of the TSRO models is more reasonable and balanced.

After careful analysis, it can be found that the distribution route cost is a large part of the total cost under the TSSO model. Although this planning method can guarantee the stable supply of materials and meet the rescue needs, there would still be some problems in the specific service path planning. For example, the cost of long-distance transportation will be increased; the roundabout transportation will be caused by the crossed distribution paths, which will increase the cost; the main disaster relief spots are not used properly, which will cause the subsequent transportation costs to increase; once there is uncertainty in the actual rescue process, it will be more uncertain than the fluctuation of demand, and the stability and perseverance of the model will be randomly improved in two stages. In this way, the logistics of the rescue materials will face some challenges and difficulties. Therefore, in the process of production operation, we must make a reasonable plan and find out a better improvement strategy.

As can be seen in Figure 4, the two largest increasing transfer cold storages increase by $25.9 \%$ and $12.0 \%$, respectively, and the two largest decreasing sites are $C 2, C 4$, respectively, $-11.5 \%$ and $-14.7 \%$. The change of site inventory directly affects the change of total cost. In the sites with increasing transshipment proportion, the BTSRO model takes on more distribution tasks than the TSSO

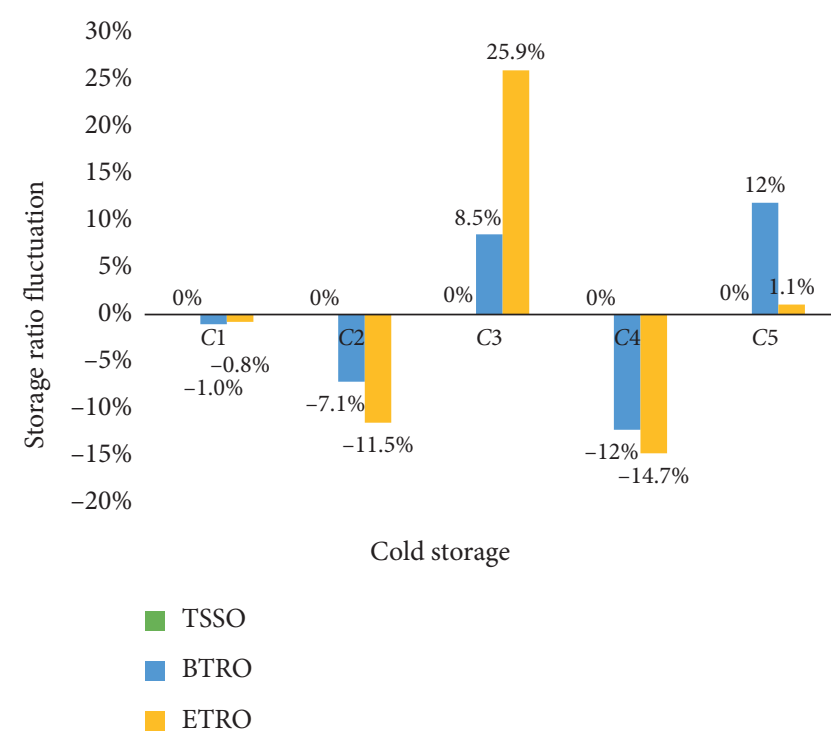

FIGURE 4: Change range of inventory proportion of cold storages.

model. In the path planning of the second stage, $C 3$ takes on more distribution tasks and the transshipment proportion increases by $8.5 \%$. The ETSRO model is compared with the TSSO model. In the second stage of path planning, the proportion of transit increases by $25.9 \%$.

In the sites with reduced transshipment proportion, in the stage of path planning, the BTSRO model is compared with the TSSO model, and the transshipment proportion of the cold storage $C 2$ is reduced by $7.1 \%$. Compared with the TSSO model, the transit proportion of the ETSRO model decreases by $11.5 \%$. In the second stage of path planning, the BTSRO model is compared with the TSSO model, and the cold storage transfer proportion decreased by $12.0 \%$. Compared with the TSSO model, the transit ratio of the TSRO model in ellipsoid set decreases by $14.7 \%$. In the second stage of path planning, the BTSRO model is compared with the TSSO optimization model, and the transfer proportion of $C 4$ decreases by $12.0 \%$. Compared with the TSSO model, the transit ratio of the TSRO model in ellipsoid set decreases by $14.7 \%$.

In the second stage of path planning, the proportion of transit is relatively balanced in each major transfer center, and the transit capacity and load pressure of each designated hospital are relatively balanced. As can be clearly seen in Figure 5, site C3 goes deeper into the hinterland and is closer to the demand site, which makes path planning more reasonable. Compared with BTSRO, the ETSRO model further reduces the proportion of long-distance line transportation and increases the proportion of short-distance transportation, especially after fully utilizing C3. Comparatively speaking, the service proportion in each path tends to be short-haul route, which bears less cost and therefore increases the proportion of material supply. As a result, on-board mileage is more efficient, and delivery routes are more accurate and fast, showing better optimization performance. For warehousing-transportation optimization with uncertain demand, a TSRO model is 


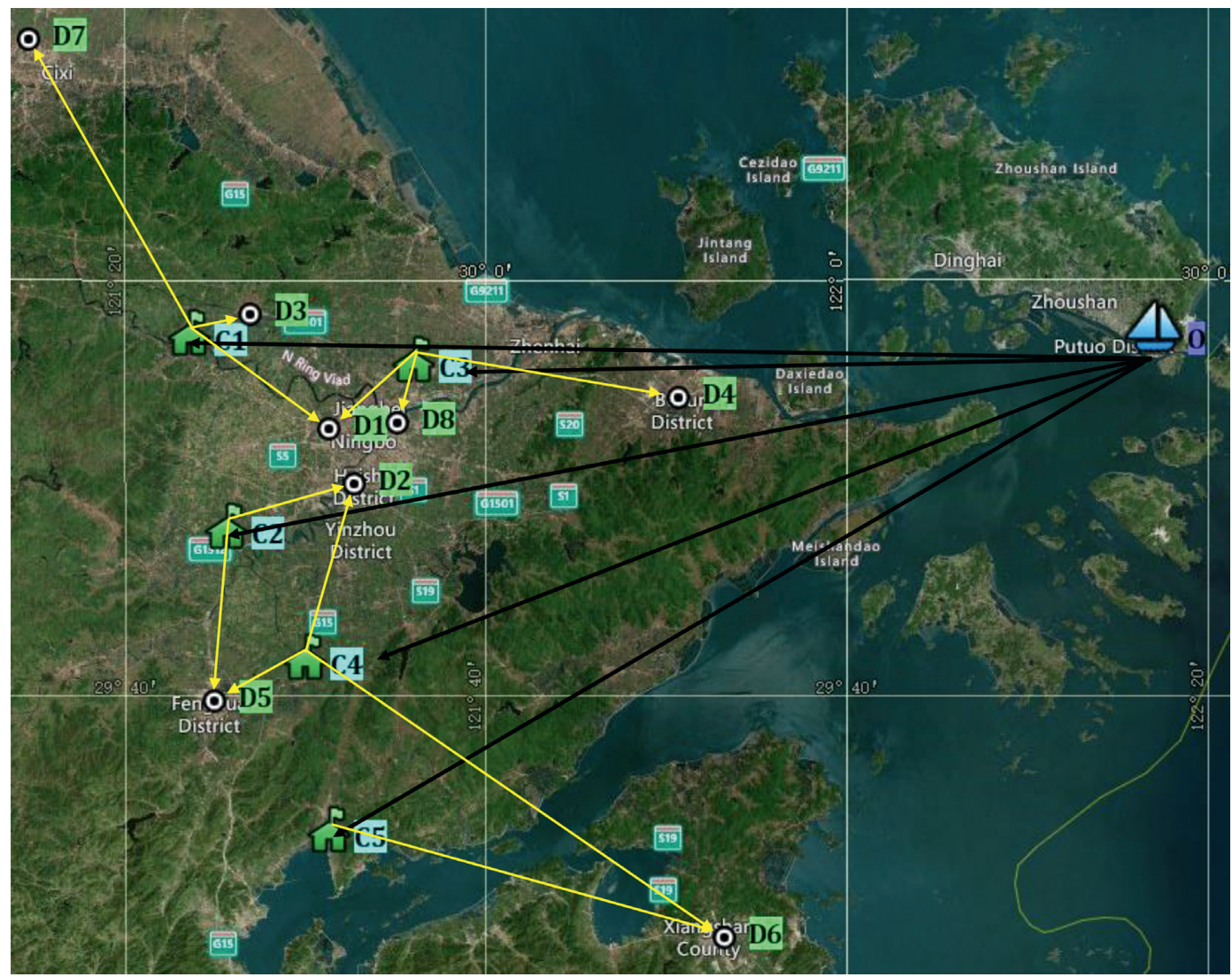

FIGURE 5: Optimal path planning scheme.

constructed by data-driven method. The uncertain set contains probability distribution functions with equal first and second moment. Compared with traditional stochastic optimization model, the established model is more robust in numerical simulation.

\section{Parameter Sensitivity Analysis}

This section provides a comparative analysis of the performance of each model, including the impact of carbon tax costs and safety parameters on total costs and service levels. The model performance is analyzed by Level of Service (SL). Due to the high requirement for timeliness of material dispatch in logistics management, this section compares SL of different models through time differences and analyzes the advantages and disadvantages. The SL is calculated as follows:

$$
\mathrm{SL}=\left[1-\frac{\sum_{J}\left(y_{i j}\right) \widetilde{D}_{j} d_{i j} / \bar{v}-t_{j} \sum_{J} \widetilde{D}_{j}}{t_{j} \sum_{J} \widetilde{D}_{j}}\right] \times 100 \%,
$$

where $I, J$ is the indicator parameter in the model. The simulation results under different parameters are as follows.

From Figure 6, it can be seen that, as a whole, the TSRO model has better robustness than the TSSO model. When the cost of carbon tax per unit increases from 0.0 to 4.0 , the cost of TSSO model increases the most, much higher than that of TSRO model. From the details, the ETSRO model is better optimized than the BTSRO model. The cost of the

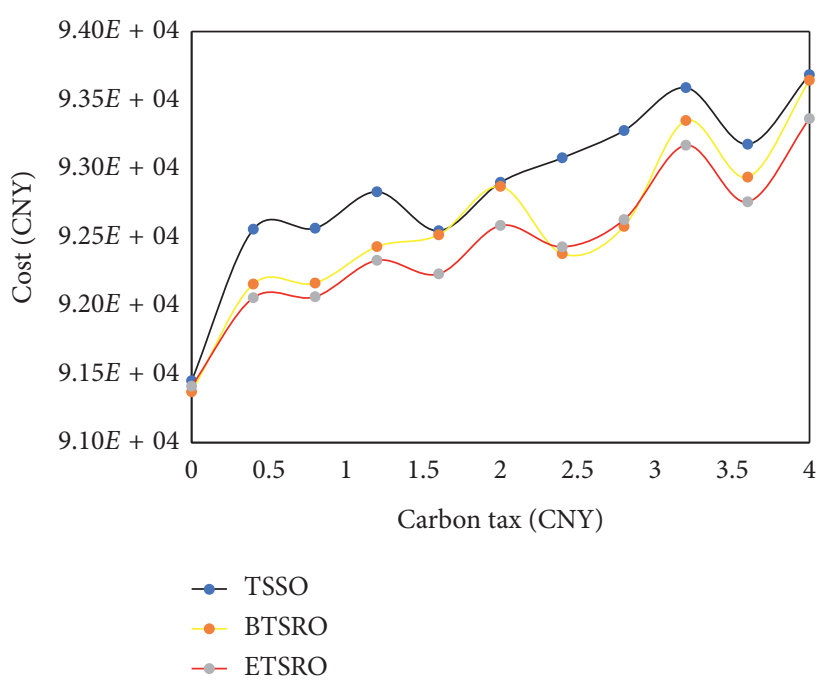

FIgURE 6: The impact of carbon emission cost on total cost.

ETSRO model grew slowly and increased slightly $(+2.18 \%)$. The rising cost of carbon emissions will lead to the rise of total costs. Therefore, policymakers can implement certain restriction strategies to achieve environmental benefits in the implementation of sustainable development strategies.

Figure 7 analyzes the impact of carbon tax on SL. On the whole, with the increase of carbon tax cost, the SL of the 


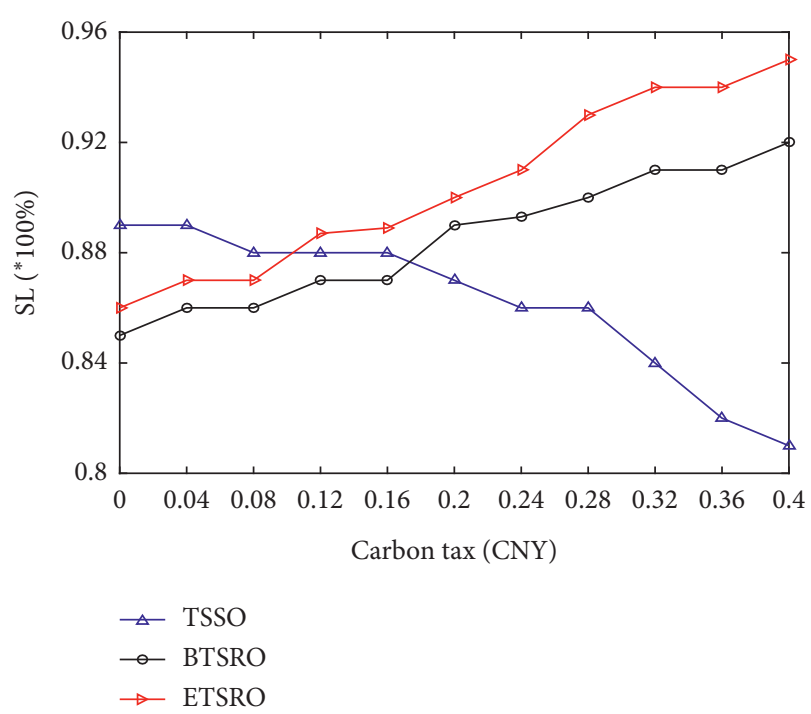

Figure 7: The impact of carbon tax on logistics service level.

TSSO model shows a downward trend, while the SL of the TSRO model shows an upward trend. Details show that there are differences in the rising cost trends of the TSRO model. Comparatively, the BTSRO shows more obvious trend of increasing SL and better optimization performance than the ETSRO model.

\subsection{Influence of Safety Parameters and Their Responsiveness.} Figure 8 analyzes the effect of safety parameters on total cost (fixed volatility is 0.15 ). It can be seen that, with the increase of safety parameters, the total cost of logistics distribution is on the rise as a whole. Different two-stage robust optimization models have different rate of cost increase, while the two-stage stochastic optimization model is not affected by safety parameters and can be used as a reference standard. The box set two-stage robust optimization model increases the cost at the highest rate and pays the greatest robustness cost for improving the safety level. The ETSRO model is the most stable and pays the lowest price due to the increase of safety parameters.

Figure 9 illustrates the impact of safety parameters on the service level of the model with a fixed level of stochastic volatility $(\varepsilon=0.10)$. Overall, with the increase of security level, logistics service level shows an increasing trend. This variable compensates for the increased total cost due to uncertainty and mitigates the loss of reduced service levels due to random volatility. Careful comparison shows that the ETSRO model has strong robustness. When the safety parameters increase from 1 to 8 , the logistics service level increases from $85.83 \%$ to $92.97 \%$ during the path planning phase. The performance improvement of the BTSRO model is relatively low, and the logistics service level increases from $85.67 \%$ to $90.16 \%$. In the process of logistics transportation, managers must pay attention to fast responsiveness. Considering uncertainties, although the TSRO model can give path planning plans, the performance and application range of each scheme are also different. Therefore, decision-makers

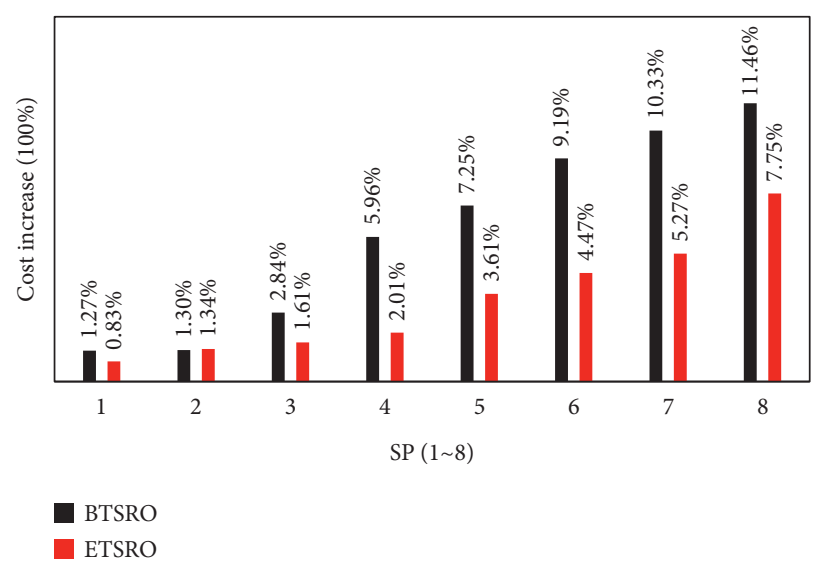

FIGURE 8: Impact of total cost with safety parameter.

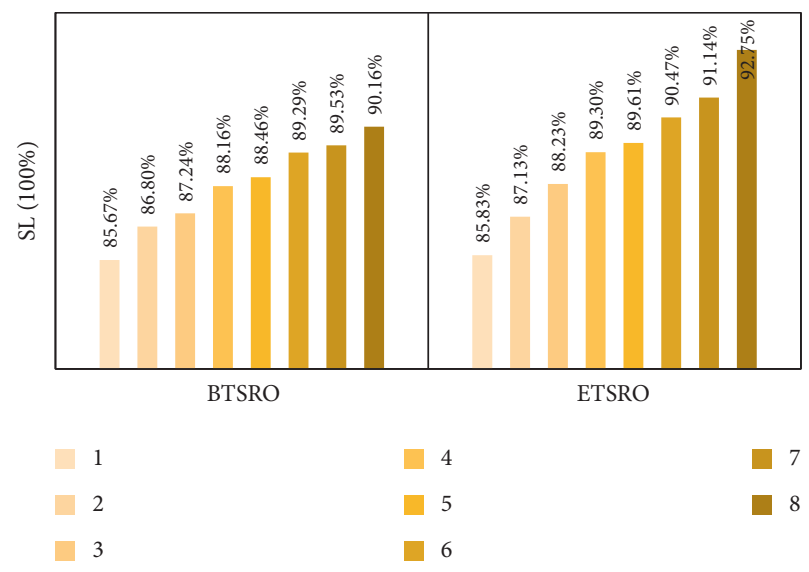

FIGURE 9: Impact of safety parameters on logistics service level.

must review the situation and make the most reasonable path planning plan according to local conditions. Decisionmakers need to weigh the various objectives against the actual situation and trends of the epidemic and choose the ideal alternative for decision-making. Ideally, limited resources should be fully utilized while minimizing all costs to achieve cost savings and environmental protection.

\section{Conclusion}

With the continuous improvement of people's living standards, the demand for cold chain logistics is also increasing. Low carbon economy has also become the key word of logistics development.

In this paper, from the perspective of low-carbon economy, considering fixed costs comprehensively, the cold chain logistics distribution routing optimization is analyzed. A low carbon two-stage stochastic optimization model is established to solve the problem. The two-stage robust optimization model is further constructed to resist uncertain disturbances. The practicability, reliability, and stability of the two-stage model are verified by taking a fresh and cold 
chain logistics transportation enterprise in the eastern coastal area of China as an example.

The simulation results show that the model proposed in this paper can solve the inventory routing optimization problem of cold chain low carbon logistics distribution in a short time.

This hybrid approach enables rational route planning, reduces overall costs and carbon emissions, and ensures the quality of logistics services. When carbon tax increases, forcing enterprises to choose a better distribution route will not only save costs but also obtain certain environmental benefits. This finding can provide some enlightenment for low-carbon transformation and development of cold chain logistics enterprises. For complex network distribution models with numerous demand stations, this paper constructs a target model and algorithm, which takes equity and efficiency into account.

This model can obtain route planning plans under different conditions in effective time, more closely match the actual situation of capital distribution, and provide more decision-making options for decision-makers. This study has the following limitations: The premise of this study is the supply chain, without considering the situation of insufficient supply. In addition, there are a lot of direct sales and direct transportation in real life, which may be the focus of future research. Low-carbon economy is widely promoted in China. The model provides theoretical support for the transformation and sustainable development of cold chain logistics enterprises. Cold chain logistics is a complex system that is affected by various attributes. In addition, this parameter configuration has not been fully verified in previous studies.

Future research may improve the proposed model and parameter configuration. The development of cold chain logistics informatization is the latest trend of logistics industry development.

\section{Data Availability}

No data were used in this study.

\section{Conflicts of Interest}

The authors declare that they have no conflicts of interest.

\section{References}

[1] J. Jiang, D. Xie, B. Ye, B. Shen, and Z. Chen, "Research on China's cap-and-trade carbon emission trading scheme: overview and outlook," Applied Energy, vol. 178, pp. 902-917, 2016.

[2] B. Guri, G. Victor David, and S. Andresen, "California's capand-trade system: diffusion and lessons," Global Environmental Politics, vol. 17, no. 3, pp. 12-30, 2017.

[3] W. Li, S. Sun, and H. Li, "Decomposing the decoupling relationship between energy-related $\mathrm{CO}_{2}$ emissions and economic growth in China," Natural Hazards, vol. 79, no. 2, pp. 977-997, 2015.

[4] S. Lu, H. Jiang, Y. Liu, and S. Huang, "Regional disparities and influencing factors of average $\mathrm{CO}_{2}$ emissions from transportation industry in Yangtze river economic belt,"
Transportation Research Part D: Transport and Environment, vol. 57, pp. 112-123, 2017.

[5] K. Kang, Y. Zhao, J. Zhang, and C. Qiang, "Evolutionary game theoretic analysis on low-carbon strategy for supply chain enterprises," Journal of Cleaner Production, vol. 230, pp. 981-994, 2019.

[6] B. Yin and Y. Liu, "An exploration of residents' low-carbon awareness and behavior in Tianjin, China," Energy Policy, vol. 61, pp. 1261-1270, 2013.

[7] L. Qi, Q. Zhao, and B. Lev, "Cold chain transportation decision in the vaccine supply chain," European Journal of Operational Research, vol. 283, no. 1, pp. 182-195, 2019.

[8] N. Stern, Stern Review: The Economics of Climate Change, Cambridge University Press, Cambridge, UK, 2006.

[9] S. Mercier, S. Villeneuve, M. Mondor, and I. Uysal, "Timetemperature management along the food cold chain: a review of recent developments," Comprehensive Reviews in Food Science and Food Safety, vol. 16, no. 4, pp. 647-667, 2017.

[10] A. Sbihi and R. W. Eglese, "Combinatorial optimization and green logistics,” 4OR, vol. 5, no. 2, pp. 99-116, 2007.

[11] K. M. R. Hoen, T. Tan, J. C. Fransoo et al., "Effect of carbon emission regulations on transportmode selection under stochastic demand," Flexible Services and Manufacturing Journal, no. 26, pp. 170-195, 2012.

[12] Z. Zhou, L. Nie, H. Ji, H. Zeng, and X. Chen, “Does a firm's low-carbon awareness promote low-carbon behaviors? empirical evidence from China," Journal of Cleaner Production, vol. 244, Article ID 118903, 2019.

[13] S. Tang, W. Wang, H. Yan, and G. Hao, "Low carbon logistics: reducing shipment frequency to cut carbon emissions," International Journal of Production Economics, vol. 164, pp. 339-350, 2015.

[14] M. Hariga, R. As'ad, and A. Shamayleh, "Integrated economic and environmental models for a multi stage cold supply chain under carbon tax regulation," Journal of Cleaner Production, vol. 166, pp. 1357-1371, 2017.

[15] S. Elhedhli and R. Merrick, "Green supply chain network design to reduce carbon emissions," Transportation Research Part D: Transport and Environment, vol. 17, no. 5, pp. 370379, 2012.

[16] E. Nikzad, M. Bashiri, and F. Oliveira, "Two-stage stochastic programming approach for the medical drug inventory routing problem under uncertainty," Computers \& Industrial Engineering, vol. 128, pp. 358-370, 2019.

[17] P. Yasari, M. Ranjbar, N. Jamili, and M.-H. Shaelaie, "A twostage stochastic programming approach for a multi-objective course timetabling problem with courses cancelation risk," Computers \& Industrial Engineering, vol. 130, pp. 650-660, 2019.

[18] D. Mary, F. Oliveira, and A. Babak, "A two-stage stochastic programming model for inventory management in the blood supply chain," International Journal of Production Economics, vol. 187, pp. 27-41, 2017.

[19] W. Christoph, K. Achim, and S. Frank, "A two-stage stochastic programming approach for identifying optimal postponement strategies in supply chains with uncertain demand," Omega-international Journal of Management Science, vol. 83, pp. 123-138, 2018.

[20] X. Chen, A. Shapiro, and H. Sun, "Convergence analysis of sample average approximation of two-stage stochastic generalized equations," SIAM Journal on Optimization, vol. 29, no. 1, pp. 135-161, 2019.

[21] X. Chen, H. Sun, and H. Xu, "Discrete approximation of twostage stochastic and distributionally robust linear 
complementarity problems," Mathematical Programming, vol. 177, no. 1-2, pp. 255-289, 2019.

[22] F. Lin, T. Jia, F. Wu, and Z. Yang, "Impacts of two-stage deterioration on an integrated inventory model under trade credit and variable capacity utilization," European Journal of Operational Research, vol. 272, no. 1, pp. 219-234, 2019.

[23] B. Sainathuni, P. J. Parikh, X. Zhang, and N. Kong, "The warehouse-inventory-transportation problem for supply chains," European Journal of Operational Research, vol. 237, no. 2, pp. 690-700, 2014.

[24] M. Francesca, A. Potra Florian, and B. Marida, "A scenariobased framework for supply planning under uncertainty: stochastic programming versus robust optimization approaches," Computational Management Science, vol. 14, no. 1, pp. 5-44, 2017.

[25] V. Rakesh and K. Adil Gajendra, "Designing a block stacked warehouse for dynamic and stochastic product flow: a scenario-based robust approach," International Journal of Production Research, vol. 57, no. 5, pp. 1345-1365, 2019.

[26] R. Ahmad, D. Farzad, F. Behnam et al., "Green supply chain network design with stochastic demand and carbon price," Annals of Operations Research, vol. 250, no. 2, pp. 1-23, 2017.

[27] X. Wang, N. Fan, and P. M. Pardalos, "Robust chance-constrained support vector machines with secondorder moment information," Annals of Operations Research, vol. 263, no. 1-2, pp. 45-68, 2018.

[28] G. Nalan, A. Pachamanova Dessislava, and C. Ethem, "Robust strategies for facility location under uncertainty," European Journal of Operational Research, vol. 225, no. 1, pp. 21-35, 2013.

[29] Z. Shiva, J. Armin, F. Behnam et al., "Robust supply chain network design: an optimization model with real world application," Annals of Operations Research, vol. 257, no. 1, pp. 15-44, 2017.

[30] Y. Lu, Y. Xu, E. Herrera-Viedma, and Y. Han, "Consensus of large-scale group decision making in social network: the minimum cost model based on robust optimization," Information Sciences, vol. 547, pp. 910-930, 2021.

[31] S. Qu, Y. Xu, Z. Wu et al., "An interval-valued best-worst method with normal distribution for multi-criteria decisionmaking," Arabian Journal for Science and Engineering, 2020.

[32] C. B. Karaku, D. Demirolu, A. Oban et al., "Evaluation of GISbased multicriteria decision making methods for sanitary landfill site selection: the case of Sivas city, Turkey," Journal of Material Cycles and Waste Management, vol. 22, no. 1, pp. 254-272, 2020.

[33] S. Qu, H. Cai, and N. Mohamed, "Correction to: uncertainty in the prediction and management of $\mathrm{CO}_{2}$ emissions: a robust minimum entropy approach," Nat Hazards, 2021.

[34] A. Ben-Tal and A. Nemirovski, "Robust solutions of uncertain linear programs," Operations Research Letters, vol. 25, no. 1, pp. 1-13, 1999.

[35] W. J. Bell, L. M. Dalberto, M. L. Fisher et al., "Improving the distribution of industrial gases with an on-line computerized routing and scheduling optimizer," Interfaces, vol. 13, no. 6, pp. 4-23, 1983.

[36] J. Goldberg, "Operations research models for the deployment of emergency services vehicles," EMS Management Journal, vol. 1, no. 1, pp. 20-39, 2004.

[37] C. Araz, H. Selim, and I. Ozkarahan, "A fuzzy multi-objective covering-based vehicle location model for emergency services," Computers \& Operations Research, vol. 34, no. 3, pp. 705-726, 2007.
[38] L.-Y. Zhang, M.-L. Tseng, C.-H. Wang, C. Xiao, and T. Fei, "Low-carbon cold chain logistics using ribonucleic acid-ant colony optimization algorithm," Journal of Cleaner Production, vol. 233, pp. 169-180, 2019.

[39] Y. Min and N. Anna, "Competitive food supply chain networks with application to fresh produce," European Journal of Operational Research, vol. 224, no. 1, pp. 273-282, 2013.

[40] M.-C. Wang, C.-Y. Liu, and A.-S. Shiao, "Water penetration into Middle ear through ventilation tubes in children while swimming," Journal of the Chinese Medical Association, vol. 72, no. 2, pp. 72-75, 2009.

[41] L. Zhang, Y. Wang, T. Fei, and H. Ren, "The research on low carbon logistics routing optimization based on DNA-ant colony algorithm," Discrete Dynamics in Nature and Society, vol. 2014, Article ID 893851, 13 pages, 2014.

[42] A. L. Soyster and F. H. Murphy, "Data driven matrix uncertainty for robust linear programming," Omega, vol. 70, pp. 43-57, 2017.

[43] Y. Shi, T. Boudouh, and O. Grunder, "A robust optimization for a home health care routing and scheduling problem with consideration of uncertain travel and service times," Transportation Research Part E: Logistics and Transportation Review, vol. 128, pp. 52-95, 2019.

[44] V. Cacchiani, J. Qi, and L. Yang, "Robust optimization models for integrated train stop planning and timetabling with passenger demand uncertainty," Transportation Research Part B: Methodological, vol. 136, pp. 1-29, 2020.

[45] A. M. Mohammad, A. Aal, and S. Z. Selim, "Robust optimization for selective newsvendor problem with uncertain demand," Computers \& Industrial Engineering, vol. 135, pp. 838-854, 2019.

[46] A. Chassein and M. Goerigk, "Minmax regret combinatorial optimization problems with ellipsoidal uncertainty sets," European Journal of Operational Research, vol. 258, no. 1, pp. 58-69, 2017.

[47] Y. Ye and J. Wang, "Study of logistics network optimization model considering carbon emissions," International Journal of System Assurance Engineering and Management, vol. 30, no. 10, pp. 1-7, 2013.

[48] J. Guo, X. Wang, S. Fan, and M. Gen, "Forward and reverse logistics network and route planning under the environment of low-carbon emissions: a case study of Shanghai fresh food E-commerce enterprises," Computers \& Industrial Engineering, vol. 106, pp. 351-360, 2017. 